\title{
VULNERABILITIES OF COASTAL COMMUNITIES RESULTING FROM CLIMATE CHANGE: A CASE STUDY OF SAN MATEO, BELIZE
}

\author{
A. BELL, R. DUGGLEBY III \& A. KINCH \\ Florida State University.
}

\begin{abstract}
This paper focuses on the migration patterns of residents of the community of San Mateo, San Pedro, Belize. Recent research conducted in the community of San Mateo by Florida State University faculty and students revealed numerous vacant lots along the coast and in areas where water has risen and not been displaced. In total, the vacant lots accounted for nearly a quarter of the community. Drawing from these findings, this paper argues that these vacant lots are due to environmental changes in the community, most likely attributed to climate change. This paper will examine environmental migration in San Mateo as well as availability of resources such as electricity and water. The ultimate goal of this research is to assess how the resettlement of environmental migrants is impacted by the availability of resources. The paper will subsequently illustrate that Central America is especially prone to the effects of climate change, and that this directly impacts the most vulnerable, coastal communities.

Keywords: Belize, case study, climate change.
\end{abstract}

\section{INTRODUCTION}

The Disaster Incident Research Team (DIRT), consisting of faculty, staff, and student researchers of the Emergency Management and Homeland Security (EMHS) Program at Florida State University, recently completed field research in San Mateo, Ambergris Caye, Belize, gathering information on demographics and resources within the community. The project was divided into two parts. The first team, comprised of EMHS staff and student researchers, surveyed San Mateo community members to gather data on the community's vulnerabilities to disaster. Community members were asked primarily about infrastructure, utilities, and bills and taxes paid to the local government. The second team of the project involved members of EMHS faculty and staff, making up the small Unmanned Aerial System (sUAS) flight operations team, who flew several missions throughout San Mateo. Employing the use of aerial photography, the team took photos and recorded video of the community so as to construct orthographic photos and gain a better understanding of the physical aspects of San Mateo.

\section{SAN MATEO, SAN PEDRO, BELIZE}

San Mateo is a small community on the island of Ambergris Caye in Belize. A community composed primarily of immigrants and other marginalized populations, San Mateo has historically been subjected to limited access to clean water, electricity, and economic opportunities for its residents. This is due to a number of factors, though primarily because local government officials claim that San Mateo is 'not [our] priority' [1]. Despite the low 
cost of living for residents and immigrants to the San Mateo neighborhood, there are clear detriments to quality of life and resource security.

Further, and although we cannot provide accurate comparative population numbers, we posit that the high number of vacant lots (about a quarter of the total number of lots in San Mateo), especially those along the coastline, is due to the effects of climate change on this particularly low-lying area. This is an area where climate change is not only visually apparent but experienced firsthand by the community, which is why the Belizean government is taking steps to combat the effects of such detrimental effects to coastal communities. According to the Inter Press Service [2], the recently launched Marine Conservation and Climate Adaptation Project will explore and develop strategies to help coastal communities become more resilient to climate change, and help people learn how they make changes to adapt to environmental factors. Belize, along with many other coastal nations in the Caribbean and the rest of the world, will undoubtedly benefit from such efforts.

\subsection{Community profile}

As of 2008, the population of the larger city of San Pedro on Ambergris Caye was reported to be 11,600 persons [3]. The community of San Pedro is located on the south side of Ambergris Caye and is the only town on the island [3]. The city is quite small but boasts impressive mercantile abilities for such a small island. The narrow streets necessitate the use of golf carts for most transportation, as average cars and trucks would be cumbersome and bulky in the streets of San Pedro, although a small number are now permitted for use.

San Mateo is an impoverished neighborhood next to the city of San Pedro. San Mateo has roughly 350 private lots, with many lots possessing multiple households, buildings, and various multi-use structures. According to the Revised Master Development Plan for Ambergris Caye compiled by Malikah Cardona and Kamilah Cardona in 2000, San Pedro continued to experience problems in overcrowding, an issue still present in San Mateo today [3]. The population of the community is extremely diverse, and individuals and family units in the community come from several different ancestral backgrounds. Some residents of San Mateo keep birds such as chickens and turkeys for subsistence. San Mateo is a relatively new community, with only a few residents having lived there for the past quarter of a century, and even more migrating in the last ten years. The Belizean government allots a plot of land to each Belizean citizen who elects to apply for one, which brought about the arrival of the San Mateo community. Some plots of land are completely underwater, difficult or unable to be reached by road, or are inundated with trash and refuse. Many residents assert that homes or other structures must be built quickly to assure ownership and involvement in the land, or otherwise the Belizean government may reassign the lot to another citizen candidate. Many lots within San Mateo are unable to receive water, electricity, sewer services, or a combination of all three. As a result, both structural and social surveys were completed lot by lot in San Mateo to ascertain which utilities are available at certain locations within the community.

\subsection{Access to clean water in San Mateo}

Our research in the community shows that many households continue to have inadequate access to necessary resources; most notably, only $40 \%$ of residents claimed that they 'always' have access to clean water (Fig. 1), and $81 \%$ reported to 'always' treat their water 


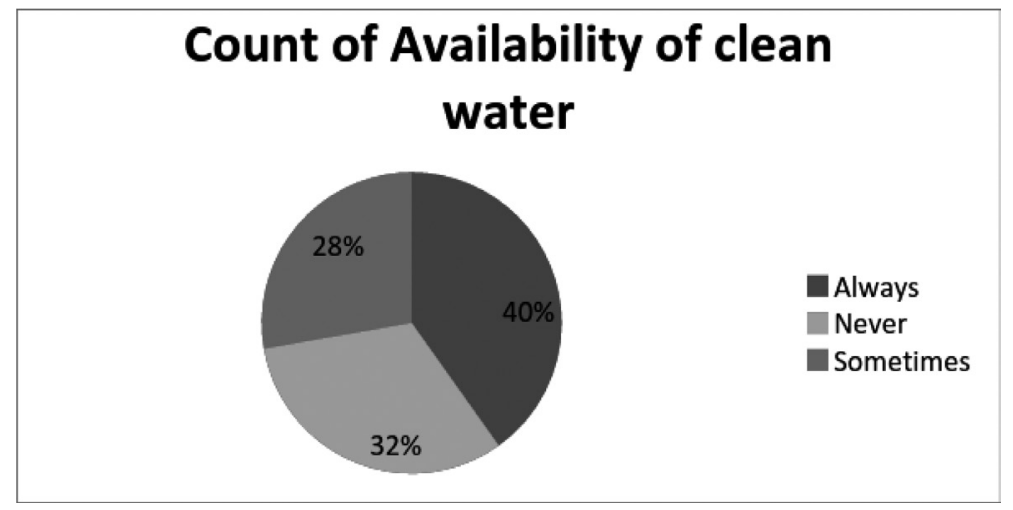

Figure 1: The slight majority of respondents stated that they have clean water available at all times. However, regardless of their response to this question, nearly every person interviewed stated that their drinking water was from bottled water purchased from Crystal Water Co. The concept of the word 'clean' proves difficult to determine.

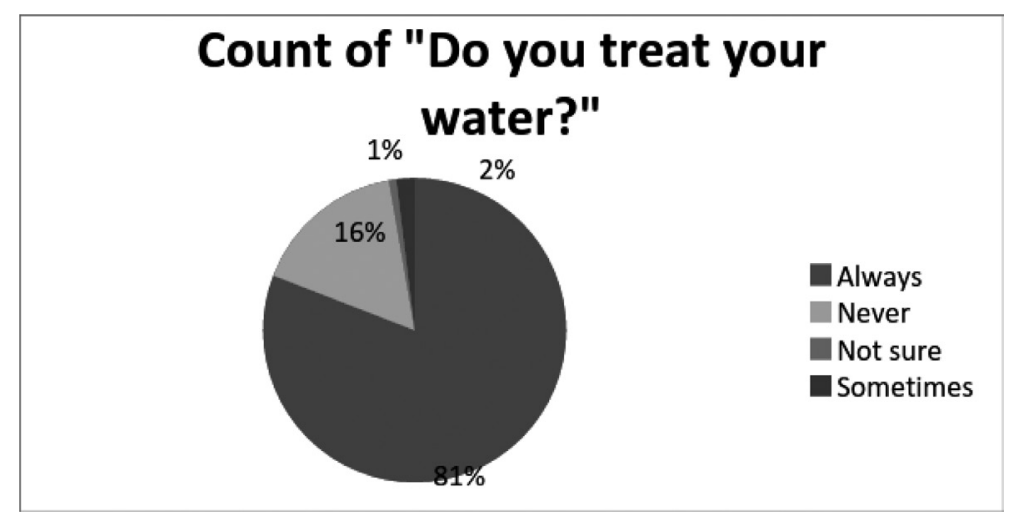

Figure 2: Due to lack of access to clean water from the tap, the residents have found that treating the water is the only alternative to purchasing it by the litre. Many homes have cisterns to collect rainwater but, per recommendation from the Red Cross Belize, even this water should be treated.

with bleach drops or tablets and/or boiling (Fig. 2). Undoubtedly, the issues of San Mateo do not typically concern the local government in San Pedro, but the fact also remains that it is markedly more difficult to route resources like water and electricity to the community. There is just one road in and out of the community, making vehicle access difficult; the dirt roads throughout San Mateo, though they have been improved in the last few years, are damaged and difficult to navigate; and most importantly, not all homes have access to San Pedro's primary water source. These factors, combined with the ever-present risks of living on a coastline in an area prone to various natural hazards, provide for a difficult living situation for San Mateo residents. 


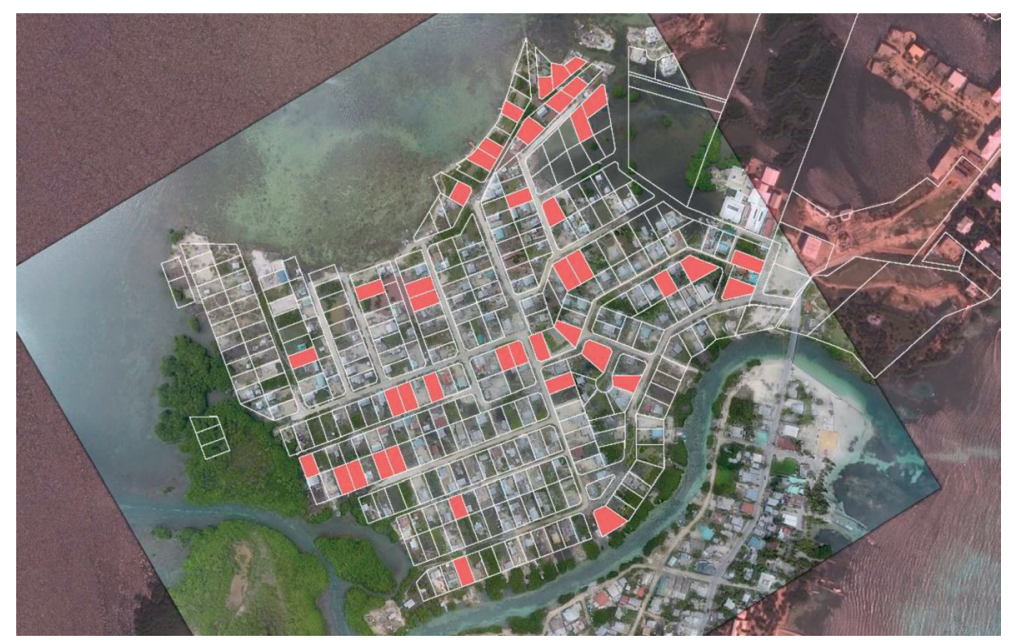

Figure 3: Lots colored in red indicate those without access to electricity.

\subsection{Electricity}

Electricity was present in 236 structures in San Mateo, yet the sources and integrity varied. The bulk of structures with power had lines originating from the main power line. These were installed approximately five to six months prior to our visit, according to the residents. Some lots had improvised power, whether split lines or a simple extension cord running from a neighbor's house. Those without electricity (Fig. 3) did not have power of any kind available in their home. Many of these lots were found on main roads.

Those lots with electricity from the main power lines were provided electrical boxes outside their homes with meters. These were either placed on the structure, on the pole, or, somewhat commonly, on cement slabs that stood along the road just outside the home. However, as stated, the residents were responsible for housing this electrical meter. The majority of the homes with power along the center of San Mateo had electrical boxes, while most of the outer lots with power did not. This indicates that the main line runs through the center of the community.

Although Belize is the recipient of year-round direct sunlight, far fewer than expected structures utilize solar power. A meager 8 structures, located away from those with reliable electricity maintained these panels. Many of those residents stated the solar panels were only used on occasion. Utilization of solar-derived electricity may be a way for the Belize government to provide reliable electricity to those residents who are not on any power line, or to discourage power sharing in the dangerous methods that have already been used. The size and capabilities of the solar panels found in San Mateo varied immensely. The majority of the few systems present had very low capabilities while a few, well-established, homes maintained systems with more extensive capacities.

\subsection{San Mateo vacant lots}

There were many vacant lots in this area. These were lots that either contained no structure at all or contained partially-built or abandoned structures. We discovered that the majority of lots were completely empty and contained only mangroves, water, or other detritus. Despite 


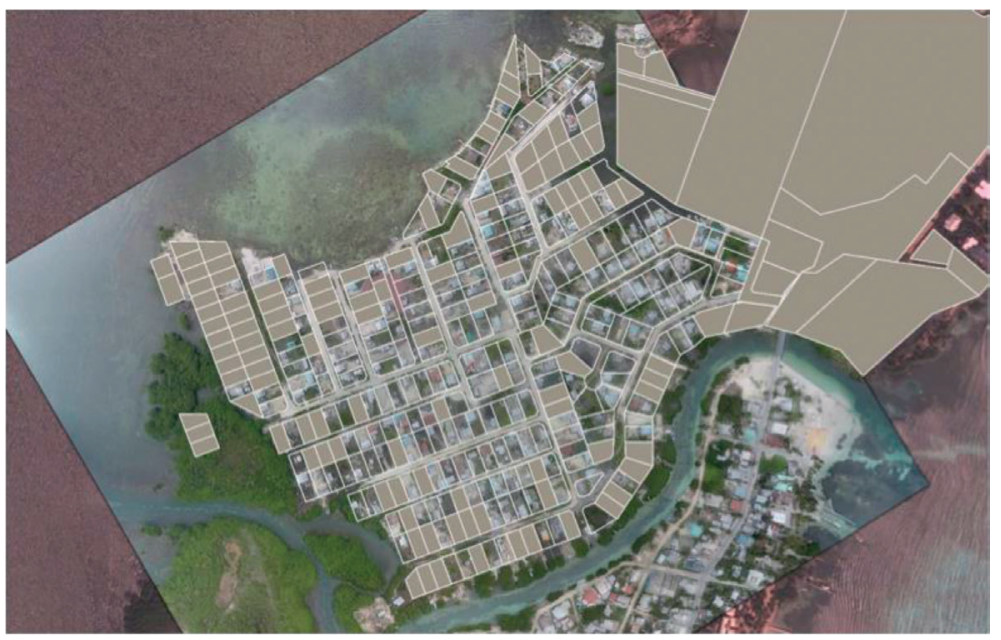

Figure 4: Vacant lots are indicated by grey fill. Some of these lots may have structures, but they are unoccupied. All other lots have residents present.

the absence of a predictable trend of vacant lot orientation, they give insight into the community's origins and future growth trends. The center of San Mateo accommodates the preponderance of the occupied lots, while vacant lots are in greater numbers along the coast or where copious inland water has yet to be displaced. Vacant lots are common along the waterway on the lower constraint (Fig. 4) or along the water in the upper right.

The vacant lots found amongst the central component of the landscape have no discernible pattern to either structure fill or location. There are 74 recorded vacant lots, or about a quarter of the community. A few had dilapidated or abandoned structures, while most were completely empty.

The Belizean government delineates the land and assigns the lots to specific individuals or families, but those who are assigned lots in such undesirable areas are solely responsible for making them livable. As such, in order to live on many of the lots in San Mateo, residents use both organic and inorganic fill by which to displace any standing or, in some cases, moving water. This includes various plastics and metals, along with Sargassum seaweed, an organic, brown macroalgae common to the region. Because of these factors, agriculture and maintaining livestock are much more difficult on San Mateo than on the rest of Ambergris Caye. Some residents of the community were even noted to have been using vacant lots for keeping chickens or goats.

\subsection{Migration from or lack of migration to San Mateo as a result of environmental factors}

Suitable living conditions and a lack of resources notwithstanding, we argue that the primary reason for the high number of empty and/or vacant lots is due in large part to the receding coastline as a result of the effects of climate change on San Mateo. This argument is strengthened when examining the global warming trends occurring in both Belize and in all of Central America.

An increase in the numbers of hurricanes and floods that have occurred in Belize provide evidence of the growing problem of climate change the country faces [4]. Additionally, rising 
temperatures are also contributing to coral bleaching. Coral bleaching can occur when reefs begin to die and can sometimes develop because of pollution or storms. However, many scientists agree that the current bleaching that is taking place in Belize is due to rising ocean temperatures [5].

These climatic changes have not only occurred in Belize but throughout Central America. According to research done by the CGIAR Research Program on Climate Change, Agriculture and Food Security, temperatures in Central America have risen since 1901 by around 0.5 [6]. Rainfall has also been more erratic since the 1950s. There have been increased delays in rain and also a greater number of rains that have occurred during the onset season [6].

These factors demonstrate the impact that climate change has had on Central America and Belize. More importantly, they illustrate the real threat to the residents of San Mateo. The numerous vacant lots with structures present point to the fact that many San Mateo residents are most likely leaving their homes due to climate change.

\section{VULNERABILITIES AND CLIMATE MIGRATION}

A significant geographic area of Belize consists of coastal cities and communities, some of which are the nation's most economically important and tourist-friendly. As such, and as R.B. Richardson notes, climate change will continue to affect these areas through increased incidence of erosion, flooding, inundation, and salinisation [7]. That we have already begun to see the detrimental effects of climate change on many island and coastal nations throughout the world is indicative that we will see such causality in Belize and the Caribbean as well.

It is also important to note that migration due to global warming can leave populations that are already vulnerable even more susceptible to problems such as food insecurity and inaccessible drinking water [8]. According to the United Nations Environment Programme, climate migration occurs when, 'Poverty, failing ecosystems, vulnerability to natural hazards,' lead to the permanent relocation of vulnerable populations [9]. As San Mateo is an impoverished community with a high number of marginalized individuals, some with a severe lack of accessibility to resources, climate migration could prove to be devastating for the community. Climate migration is already occurring in many of the Pacific island nations. It has become such a crucial issue that New Zealand has enacted an initiative known as the Pacific Access Category, in which citizens from Fiji, Kiribati, Tuvalu, and Tonga can apply for residency if their homes are severely affected by the effects of climate change [10]. San Mateo is especially susceptible to environmental factors, and as such, mitigation resources to help the community should be put into place by the Belizean government. If no steps are taken to combat this pressing issue, San Mateo faces a future similar to that of the Pacific island nations, whereby Belizean individuals and families will seek to immigrate to more developed nations.

\section{REFERENCES}

[1] Holy Cross Anglican School, available at: http://holycrossbelize.org/about-us/ san-mateo/

[2] Humes, A., "In Belize, Climate Change Drives Coastal Management." Inter Press Service, available at: http://www.ipsnews.net/2015/04/in-belize-climate-change-drivescoastal-management/, 2015.

[3] Cardona, K. \& Cardona, M., Revised Master Development Plan for Ambergris Caye. Produced for the Coastal Zone Management Authority \& Institute, 2009.

[4] UNICEF Belize-Climate Change Prevention and Emergency Response, UNICEF, available at: http://www.unicef.org/belize/climate_change_22129.htm 
134 Flood Risk Management and Response

[5] Handwerk, Brian, "Belize Reef Die off due to Climate Change?" available at: http:// news.nationalgeographic.com/news/2003/03/0325_030325_belizereefs.html

[6] Marengo, Jose, etc. all. "Climate Change in Central and South America: Recent Trends, Future Projections, and Impacts on Regional Agriculture," CGIAR Research Program on Climate Change, Agriculture and Food Security, available at: https://cgspace.cgiar. org/bitstream/handle/10568/41912/Climate\%20change\%20in\%20CA\%20and\%20 SA\%20final_.pdf?sequence $=2$

[7] Richardson, R.B., Belize and climate change: the costs of inaction, available at: http:// www.bz.undp.org/content/dam/belize/docs/UNDP\%20BZ\%20Publications/Belizeand-Climate-Change-The-Costs-of-Inaction.pdf

[8] "UNHCR - Climate Change, The Storm Ahead," The UN Refugee Agency, available at: http://www.unhcr.org/pages/49e4a5096.html

[9] "Climate Change and Environmentally Induced Migration," United Nations Environment Programme, available at: http://www.unep.org/conflictsanddisasters/Policy/ DisasterRiskReduction/ClimateChangeAndMigration/tabid/282/language/en-US/ Default.aspx

[10] "Pacific Access Category," Immigration New Zealand, available at: http://www. immigration.govt.nz/migrant/stream/live/pacificaccess/ 